\title{
The TIPS Yield Curve and Inflation Compensation ${ }^{\dagger}$
}

\author{
By Refet S. GÜRKAYNAK, BRIAN SaCK, AND Jonathan H. WrighT*
}

For over ten years, the Treasury has issued index-linked debt. This paper describes the methodology for fitting a smoothed yield curve to these securities that is used at the Federal Reserve Board every day, and makes the estimates public. Comparison with the corresponding nominal yield curve allows measures of inflation compensation to be computed. We discuss the interpretation of inflation compensation, and provide evidence that it is not a pure measure of inflation expectations being distorted by inflation risk premium and liquidity premium components. We attempt to estimate the TIPS liquidity premium and to extract underlying inflation expectations. (JEL E31, E43, H63)

F or over ten years, the US Treasury has issued Treasury Inflation-Protected Securities (TIPS) — debt securities for which the coupon and principal payments are indexed to the consumer price index (CPI) — in addition to conventional nominal bonds. However, for nominal securities and TIPS, the Treasury issues only securities with particular maturities and coupon rates. Thus, it is not possible to directly observe the nominal or real discount factors from these issues.

In a previous paper (Gürkaynak, Sack, and Wright 2007), we estimated a smoothed nominal Treasury yield curve from the outstanding off-the-run nominal Treasury notes and bonds. The results allowed us to compute the nominal discount factor, as well as to compute nominal Treasury yields and forward rates at any horizon. The first part of this paper is the sequel to Gürkaynak, Sack, and Wright (2007) that fits a similar yield curve to outstanding TIPS. The results allow us to recover the real discount function, as well as real Treasury yields and forward rates, at a daily frequency going back to 1999. These data are available in an online Appendix at www. federalreserve.gov/econresdata/researchdata.htm and are updated periodically.

A comparison of the nominal and TIPS smoothed yield curves allows us to compute measures of inflation compensation-the rate of inflation that would give an

\footnotetext{
*Gürkaynak: Department of Economics, Bilkent University, 06800 Ankara, Turkey (e-mail: refet@bilkent. edu.tr); Sack: Federal Reserve Bank of New York, 33 Liberty Street, New York, NY 10038 (e-mail: Brian. Sack@ny.frb.org); Wright: Department of Economics, Johns Hopkins University, Baltimore, MD 21202 (e-mail: wrightj@jhu.edu). We are grateful to Stefania D’Amico, Jennifer Roush, Michelle Steinberg, Min Wei, and an anonymous referee. We are also grateful to Katherine Femia for excellent research assistance. Gürkaynak gratefully acknowledges the research support of the Turkish Academy of Sciences via a TÜBA-GEBIP fellowship. All of the authors were involved in real yield curve and inflation compensation estimation at the Federal Reserve Board when working at that institution. The views expressed in this paper are solely the responsibility of the authors and should not be interpreted as reflecting the views of the Board of Governors of the Federal Reserve System or of any other employee of the Federal Reserve System.

${ }^{\dagger}$ To comment on this article in the online discussion forum, or to view additional materials, visit the articles page at: http://www.aeaweb.org/articles.php?doi=10.1257/mac.2.1.70.
} 
investor the same return on a nominal security and an indexed security at maturity. These measures are also known as breakeven inflation rates among financial market participants. These yield curves (nominal, TIPS, and inflation compensation) can be expressed in terms of zero-coupon yields, par yields, instantaneous forward rates, or $n$-by- $m$ forward rates (that is, the $m$-year rate beginning $n$ years ahead) for any $n$ and $m$.

After describing how we fit the real yield curve, we provide a discussion of how to interpret the resulting measures. We pay particular attention to the measures of inflation compensation in this regard. These measures are often thought of as being driven by investors' expectations of inflation. However, we argue that highfrequency movements in inflation compensation are considerably too volatile to represent revisions to rational expectations of inflation alone. Inflation compensation provides information about agents' inflation expectations, but its interpretation is complicated by inflation risk premia and the differential liquidity premia between TIPS and nominal securities. We provide support for this view by analyzing the time series properties of inflation compensation and actual inflation, and by comparing inflation compensation to survey respondents' inflation forecasts. Among other results, we show that inflation compensation is related to the dispersion of survey forecasts, more than to the level of those forecasts, consistent with a view that a risk premium reflecting inflation uncertainty is an important element of inflation compensation.

Section I describes the mechanics of TIPS and briefly discusses the operation of the TIPS market. Section II describes the yield curve fitting exercise. Section III shows the results of our estimation, including an assessment of the fit of the TIPS curve. Section IV provides empirical evidence indicating that inflation compensation is not a pure measure of inflation expectations. Section V delves deeper into the interpretation of inflation compensation by providing a decomposition into its components: the liquidity premium, the inflation risk premium, and inflation expectations. Section VI offers some concluding thoughts. The yield curve data described here are updated daily and posted on the Federal Reserve Board's Web site (www. federalreserve.gov/econresdata/researchdata.htm).

\section{The TIPS Market}

A nominal Treasury security pays the holder a coupon twice a year and the principal value at maturity. The coupon and principal value are fixed in nominal terms, and their real value will be eroded over time by inflation. For TIPS, the principal payment is multiplied by the ratio of the reference CPI on the date of maturity to the reference CPI on the date of issue. ${ }^{1}$ If the maturity or issue date falls on day $d_{t}$ of a month with $d_{n}$ days, then the reference CPI is

$$
\operatorname{CPI}(-2) \frac{d_{t}-1}{d_{n}}+\operatorname{CPI}(-3) \frac{d_{n}-d_{t}+1}{d_{n}},
$$

\footnotetext{
${ }^{1}$ Unless this ratio is less than one, in which case no adjustment is made. This consideration became important for newly issued bonds during the deflation scare in 2003 and again in 2008.
} 
where $C P I(-2)$ and $C P I(-3)$ denote the nonseasonally adjusted US City Average All Items Consumer Price Index for the second and third months prior to the month in which the maturity or issue date falls, respectively. The reason for the indexation lag is that the Bureau of Labor Statistics publishes these data with a lag, with the index for a given month released in the middle of the subsequent month 2 Coupons are indexed in precisely the same way. ${ }^{3}$ In effect, this gives TIPS an indexation lag of about two-and-a-half months.

The first TIPS were issued in 1997. The Treasury initially sold 5-, 10-, and 30-year TIPS. The 5-year TIPS were dropped in September 1998, and the 30-year TIPS were dropped in October 2001. Subsequently, the 5-year TIPS were reintroduced, and 20-year TIPS were added in May 2004. As of the time of this writing, there are 27 outstanding TIPS with maturity dates ranging from 2009 to 2032.

Liquidity in TIPS was initially poor, and investor participation in the market was limited, either due to lack of familiarity with the asset class or, in some cases, institutional rules preventing these securities from being held. Another important factor shaping the market was that, for a time, the long-term future of TIPS was unclear. For example, in May 2001, the Treasury Advisory Committee of the Bond Market Association recommended that the TIPS program be discontinued. However, the Treasury subsequently reaffirmed its commitment to the program, and liquidity improved substantially. TIPS now represent about 10 percent of the outstanding supply of Treasury coupon securities ${ }^{4}$ It is now the largest sovereign index-linked market in the world, measured in terms of the par value of outstanding issuance. More detail on the history and liquidity of the TIPS market is provided by Sack and Elsasser (2004).

\section{Yield Curve Fitting}

We begin this section by reviewing the fundamental concepts of the yield curve, including the necessary "bond math" for determining both nominal and TIPS yields. Then, we describe the specific estimation method employed in this paper.

\section{A. Discount Function and Zero-Coupon Yields: Nominal and Real}

The starting point for pricing any nominal fixed-income asset is the nominal discount function, or the price of a nominal zero-coupon bond. This represents the value today to an investor of a $\$ 1$ nominal payment $n$ years hence. We denote this

\footnotetext{
${ }^{2}$ David G. Barr and John Y. Campbell (1997) discuss the indexation lag for UK index-linked bonds, which was eight months for bonds issued at the time they wrote the paper.

${ }^{3}$ Except that the constraint that the adjustment factor cannot be less than one does not apply to the indexation of coupons. Thus, a period of deflation could lower the coupon payments, but the cumulative adjustment to the principal can never be negative.

${ }^{4}$ According to an informal survey of dealers conducted by the Federal Reserve Bank of New York in 2007, typical TIPS bid-ask spreads at maturities of five years or less were one-half to one tick (a tick is roughly onethirty-second of a percentage point of the price of the security). At maturities around ten years, the spread is one to two ticks. At longer maturities, the spread is four to ten ticks. These spreads are a bit tighter than those observed in 2003, as discussed by Brian Sack and Robert Elsasser (2004).
} 
as $P_{t}^{\text {nom }}(n)$. The continuously compounded yield on this nominal zero-coupon bond can be written as

$$
y_{t}^{\text {nom }}(n)=-\ln \left(P_{t}^{n o m}(n)\right) / n,
$$

and, conversely, the zero-coupon bond price can be written in terms of the yield as

$$
P_{t}^{n o m}(n)=\exp \left(-y_{t}^{\text {nom }}(n) n\right) .
$$

Here, and throughout, yields and coupon rates are expressed in percentage points. For example, 1 percent is written 0.01 .

In the same way, we consider a real discount function, or the price of a real zero-coupon bond. We denote this as $P_{t}^{\text {real }}(n)$. This represents the value today to an investor of a $\$ Q_{t+n} / Q_{t}$ payment $n$ years hence, where $Q_{t}$ denotes the price index at time $t .5$ The continuously compounded nominal yield on this bond is $\ln \left(Q_{t+n} / Q_{t} P_{t}^{\text {real }}(n)\right) / n$. The continuously compounded real yield on this bond can be written as $y_{t}^{\text {real }}(n)=-\ln \left(P_{t}^{\text {real }}(n)\right) / n$. Throughout this paper, we discuss real bonds in terms of their real yields and nominal bonds in terms of their nominal yields.

\section{B. Par Yields and Forward Rates}

There are a number of ways to express the information in the nominal yield curve in addition to continuously compounded zero-coupon yields. One way is to solve for the coupon rate, which ensures that the price of the bond today will equal its maturity price. This is known as the par yield, and it is the market convention used to describe bond yields. Par yields are quoted with semiannual compounding because coupons on US Treasury securities are paid twice per year. An alternative way of describing the yield curve is in terms of forward rates. We can solve for continuously compounded instantaneous forward rates at all horizons. Or, we can solve for $m$-year forward rates beginning $n$-years hence ${ }^{6}$

All of these concepts apply to TIPS and nominal securities, giving us two parallel sets of yields. In this paper, let $f_{t}^{n o m}(n)$ and $f_{t}^{\text {real }}(n)$ denote the $n$-period ahead nominal and real instantaneous forward rates, and let $f_{t}^{n o m}(n, m)$ and $f_{t}^{\text {real }}(n, m)$ denote the $m$-year nominal and real forward rates beginning $n$ years hence, respectively. In addition, we will use $y_{t}^{p, n o m}(n)$ and $y_{t}^{p, r e a l}(n)$ to denote the $n$-year nominal and real par yields, respectively.

\section{The Nelson-Siegel-Svensson Yield Curve}

When fitting yield curves, one faces a tradeoff between the goodness of fit and smoothness of the curve. Spline-based nonparametric curves can fit the yields of individual securities arbitrarily closely, but at the cost of being quite jagged. The

\footnotetext{
${ }^{5}$ In this discussion, we are abstracting from the indexation lag.

${ }^{6}$ To further confuse matters, the $m$-year forward rates can be expressed as either zero-coupon forward rates or par forward rates.
} 
choice, in this dimension, depends on the purpose that the yield curve is intended to serve. For example, John H. Cochrane and Monika Piazzesi (2008) argue that the fourth and fifth principal components of the nominal yield curve (that explain a tiny share of the variation in yields) are, nonetheless, very useful for forecasting excess returns. If so, in forecasting excess returns, using a smoothed curve could lose the information in the fourth and fifth principal components. On the other hand, if the purpose of the yield curve is to understand its fundamental macroeconomic determinants, a spline-based curve may produce implausibly jagged yields, and especially forward rates, that will not be very useful in macroeconomic analysis. Our TIPS yield curve is designed primarily for macroeconomic interpretation and policy analysis. Thus, rather than fitting a spline-based curve, we impose some structure on the shape by imposing a parametric form that fits the TIPS yields remarkably well. The benefit of the parametric approach is that it smoothes through the idiosyncratic movements in yields of individual securities and accurately represents the underlying shape of the (real) discount function.

The yield curves that we fit assume that the instantaneous forward rates (whether real or nominal) follow the functional form

$$
f_{t}(n)=\beta_{0}+\beta_{1} \exp \left(-n / \tau_{1}\right)+\beta_{2}\left(n / \tau_{1}\right) \exp \left(-n / \tau_{1}\right)+\beta_{3}\left(n / \tau_{2}\right) \exp \left(-n / \tau_{2}\right) .
$$

This structure was proposed by Lars E. O. Svensson (1994) and is an extension of the functional form used earlier by Charles R. Nelson and Andrew F. Siegel (1987). We refer to it as the NSS (Nelson-Siegel-Svensson) functional form. The original Nelson-Siegel functional form is a special case of (4) in which $\beta_{3}=0$. Integrating these forward rates gives us the corresponding zero-coupon yields:

$$
\begin{aligned}
y_{t}(n)=\beta_{0} & +\beta_{1} \frac{1-\exp \left(-\frac{n}{\tau_{1}}\right)}{\frac{n}{\tau_{1}}}+\beta_{2}\left[\frac{1-\exp \left(-\frac{n}{\tau_{1}}\right)}{\frac{n}{\tau_{1}}}-\exp \left(-\frac{n}{\tau_{1}}\right)\right] \\
& +\beta_{3}\left[\frac{1-\exp \left(-\frac{n}{\tau_{2}}\right)}{\frac{n}{\tau_{2}}}-\exp \left(-\frac{n}{\tau_{2}}\right)\right] .
\end{aligned}
$$

The assumed functional form of the forward rates (and, hence, yields) has some intuitive characteristics. As discussed in more detail in Gürkaynak, Sack, and Wright (2007), it allows the forward rate curve the flexibility to start and end at estimated parameters, and to have a hump-shaped pattern in between. The NelsonSiegel functional form effectively allows for only one hump, whereas the Svensson curve allows for two humps, which is important to capture convexity effects at longer horizons. The estimated parameters will determine the magnitude and location of these humps.

Given any candidate set of parameters, we can use (4) to solve for the nominal and real discount factors. With these discount factors, we can construct a predicted price 


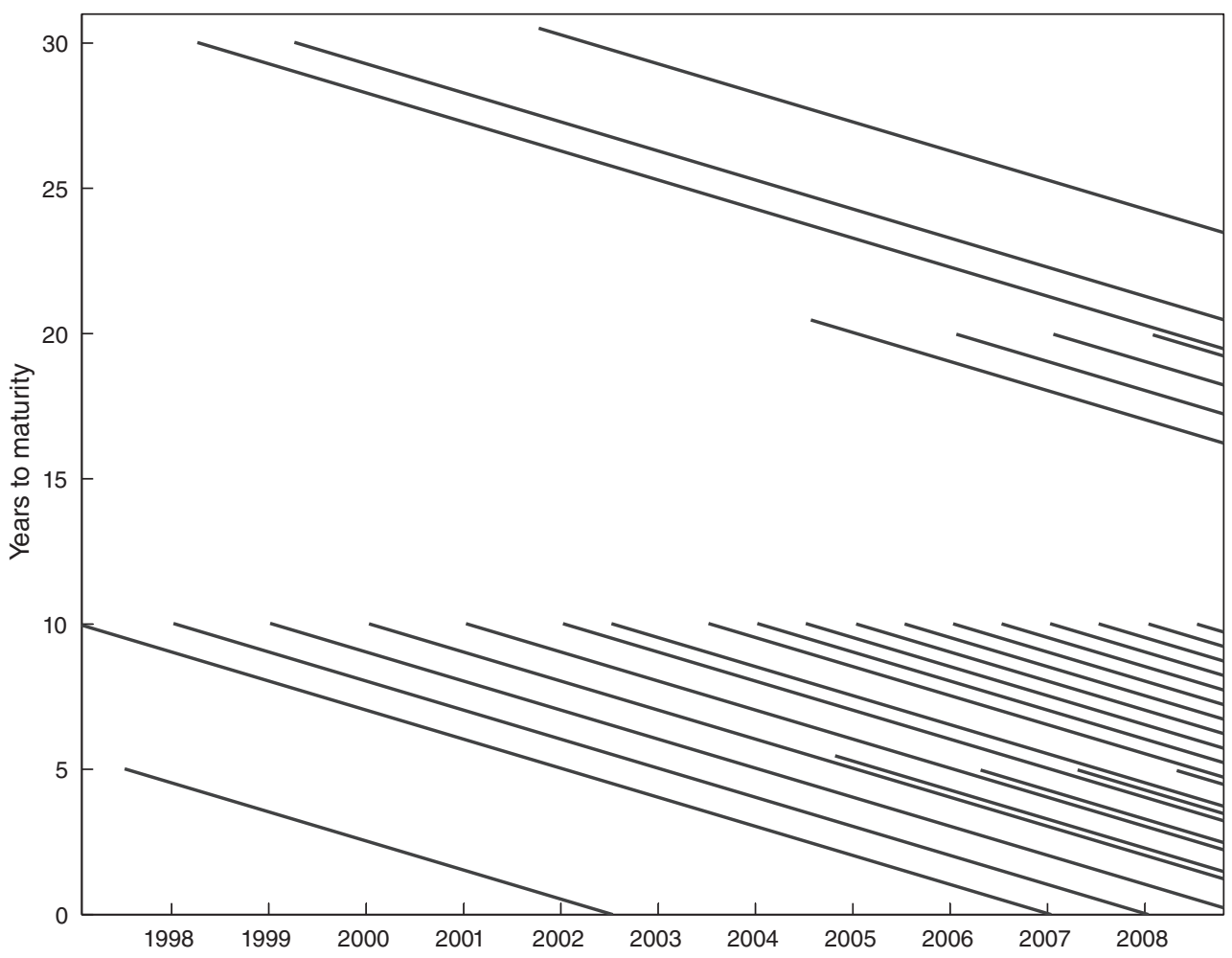

Figure 1. Outstanding TIPS Securities

for any Treasury security (nominal or real) with a given maturity date and coupon rate by considering it to be a bundle of zero-coupon securities, one corresponding to each payment on the security, with the value of each payment determined by the appropriate discount factor. We estimate the nominal and TIPS yield curves by numerically choosing the set of parameters so as to minimize the weighted sum of squared deviations between actual and predicted prices. The weights are the inverse of the durations of each individual security. ${ }^{7}$

The ranges of maturities available for estimation over our sample are shown graphically in Figure 1, which takes the same form as a figure reported by Robert R. Bliss (1996). The date is shown on the horizontal axis, the remaining maturity is shown on the vertical axis, and each outstanding TIPS security is represented by a line plotting its remaining years to maturity against the date.

As noted before, the Svensson curve allows for two humps, while the original Nelson-Siegel functional form allows for just one hump. The second hump is, however, not well identified unless we have enough long-term securities. For the nominal yield curve, we used the restricted functional form up until 1980, then switched to the Svensson parameterization because more long-term nominal Treasury securities

\footnotetext{
${ }^{7}$ Weighting price by inverse duration converts the pricing errors into yield fitting errors, to a first approximation. Fitting inverse-duration-weighted prices, rather than yields, is preferable because it is computationally much faster and delivers essentially the same yield curve.
} 
became available to estimate the shape of more distant forward rates. Following similar reasoning, and given the maturities available, as shown in Figure 1, for the TIPS yield curve, we used the more restricted functional form through the end of 2003, and then we switch to the Svensson parameterization as the issuance of 20-year TIPS helped the estimation.

TIPS with less than 18 months to maturity are dropped from the estimation of the TIPS yield curve because the effect of the indexation lag makes the prices of these securities erratic. TIPS with remaining maturity between 18 and 24 months are downweighted linearly for smooth behavior of the short-end of the curve over time. All other TIPS are included in estimation of the TIPS yield curve.

\section{Inflation Compensation}

Having computed nominal and TIPS yields, it is straightforward to solve for rates of inflation compensation. These rates are defined as the inflation rates which, if realized, would leave an investor indifferent between holding a TIPS and a nominal Treasury security.

The formula is simplest for the continuously compounded zero-coupon inflation compensation rate at maturity $n$ :

$$
\pi_{t}(n)=y_{t}^{n o m}(n)-y_{t}^{\text {real }}(n)
$$

It simply states that the cumulative amount of inflation needed to equalize the return on nominal and real zero-coupon securities, expressed as an annual inflation rate on a continuously compounded basis, is given by the difference in the nominal and real yields. Similarly, the continuously compounded instantaneous forward inflation compensation rate is

$$
\pi_{t}^{f}(n)=f_{t}^{n o m}(n)-f_{t}^{r e a l}(n)
$$

For par securities, the semi-annually compounded inflation compensation rate is given by:

$$
\pi_{t}^{p}(n)=2\left(\frac{1+\frac{y_{t}^{p, \text { nom }}(n)}{2}}{1+\frac{y_{t}^{p, \text { real }}(n)}{2}}-1\right) .
$$

\section{Yield Curve Results}

Using the methodology described above, we estimate the US TIPS yield curve using daily data from January 1999 to the present (the data used in the paper are through October 21, 2008). Our underlying quotes on individual TIPS were provided to us by Barclays Capital Markets. ${ }^{8}$ The quotes are the averages of bid and ask prices.

\footnotetext{
${ }^{8}$ We are not permitted to release the underlying data. However, the estimated yield curve is publicly available and regularly updated, as described in the text.
} 


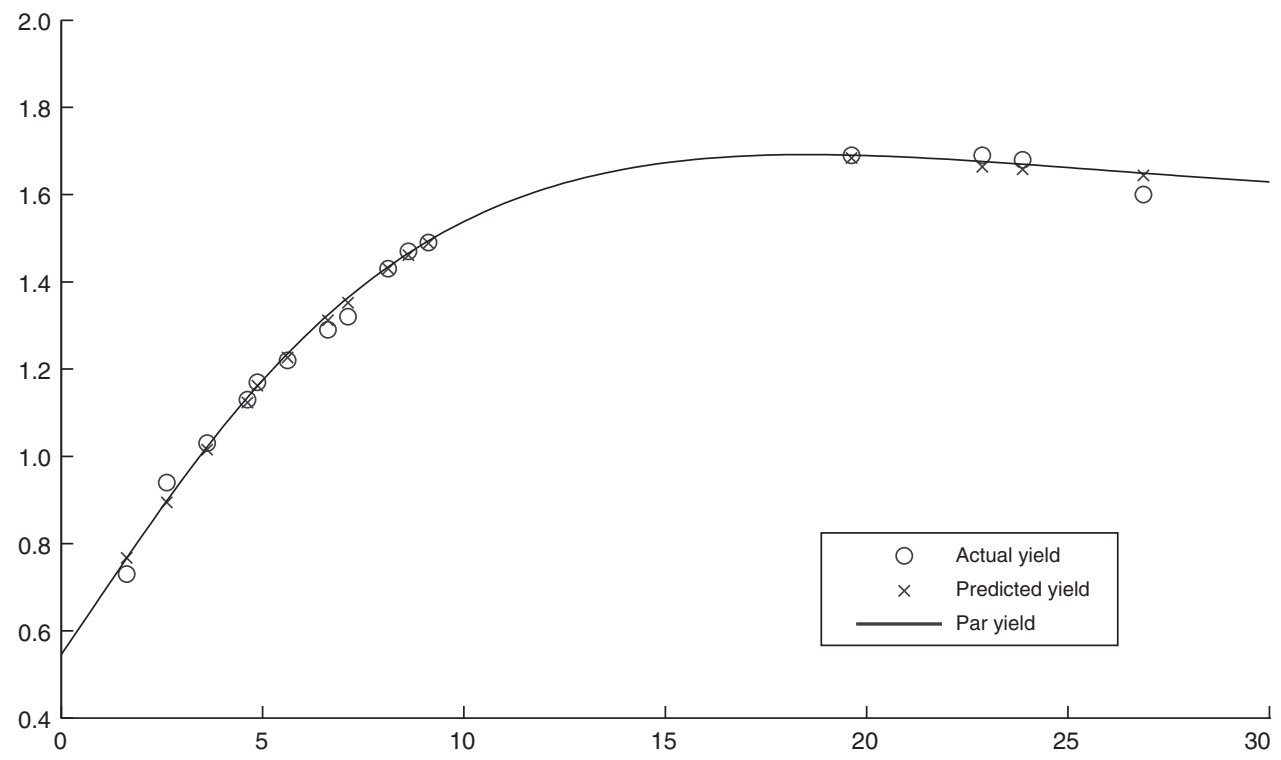

Figure 2. PAr TIPS Yield Curve ON June 1, 2005

As an example of the results, Figure 2 shows the estimated TIPS yield curve on June 1, 2005. The solid line is the continuously compounded par yield curve, the circles are the actual quotes on all outstanding coupon securities included in the estimation, and the crosses are the predicted yields for these issues.

As can be seen, the yield curve does an impressive job fitting the entire crosssection of TIPS issues with a function of only six parameters. The success at fitting TIPS yields on this date is repeated throughout the sample. Figure 3 shows the average absolute yield prediction error in different maturity buckets over time. As can be seen, all of the errors are quite small over the entire sample. The largest fitting errors tend to be seen in the very shortest (2-5 year) and longest (20-30 year) maturity buckets, and even there, the typical errors are only a few basis points.

Figure 4 returns to the specific date considered in Figure 3, only now it shows the zero-coupon TIPS yield curve and the instantaneous forward rates at all horizons, as well as the corresponding measures for inflation compensation. In June 2005, the Federal Reserve was in the middle of a tightening cycle. The TIPS yield curve sloped up at that time, reflecting expectations for the continued removal of monetary policy accommodation and, perhaps, a real interest rate risk premium that was increasing in maturity. Because of convexity effects, the upward slope of the zero-coupon TIPS yield curve tapers off at long horizons, and eventually turns down. Accordingly, the forward rates turn down earlier and much more sharply. Inflation compensation slopes down at short to intermediate maturities, perhaps reflecting expectations for a moderation in headline inflation, but then slopes up at intermediate and longer

\footnotetext{
${ }^{9}$ That is, the crosses are consistent with the par yields shown in the line. They are not exactly on the par curve because the outstanding securities are not trading precisely at par.
} 

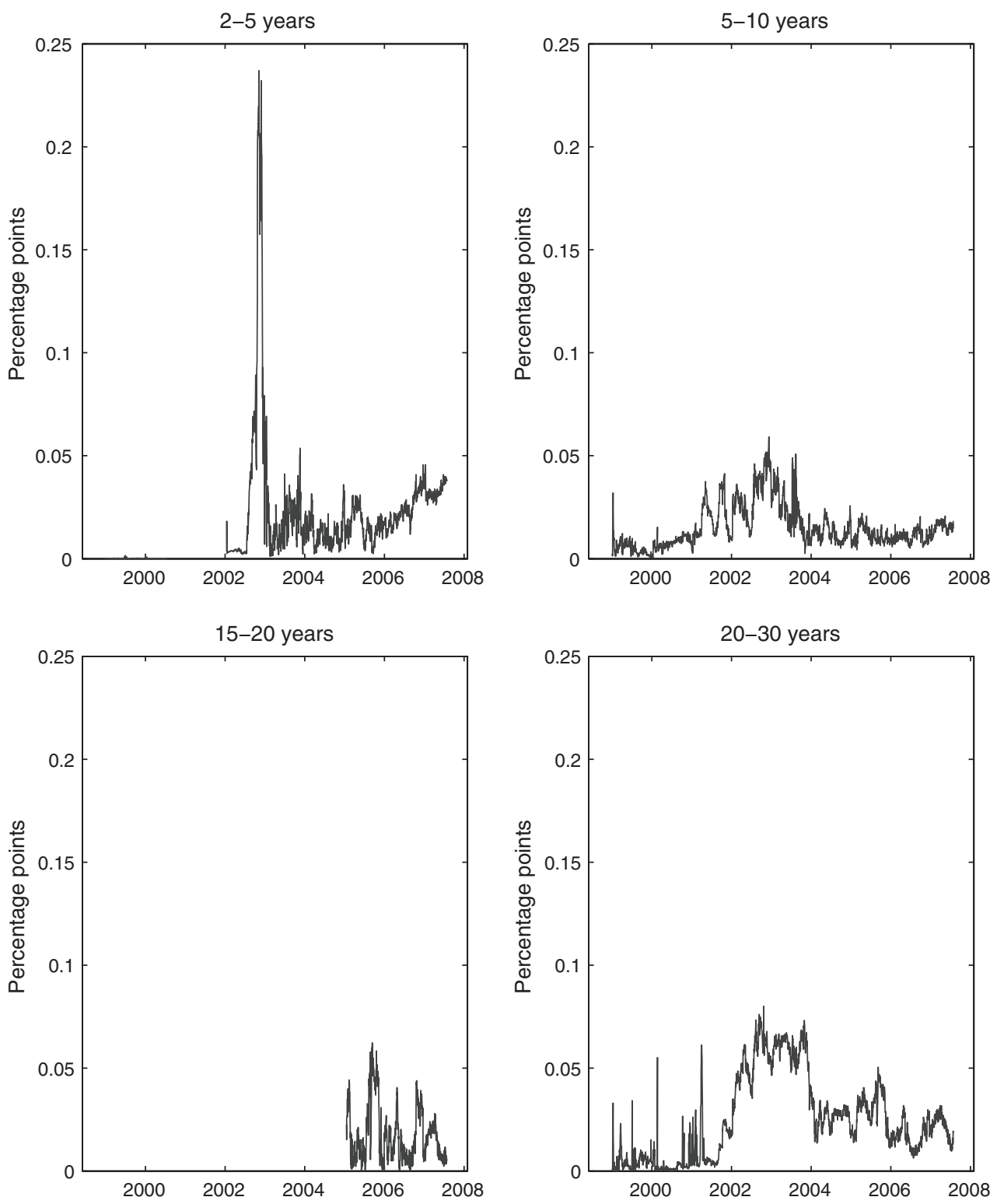

Figure 3. Average Absolute Yield Prediction Errors by Indicated Maturity Bin

maturities, presumably owing, in part, to an inflation risk premium that is increasing in maturity.

The history of 5- and 10-year zero-coupon nominal and TIPS yields is shown in Figure 5. In 1999, TIPS yields were high, reflecting, in part, the premium that investors demanded to induce them to hold these assets that were then quite illiquid. TIPS yields subsequently declined sharply as liquidity improved and the FOMC eased monetary policy to combat the 2001 recession. The FOMC began to tighten monetary policy again in the middle of 2004. Five-year zero-coupon nominal and 

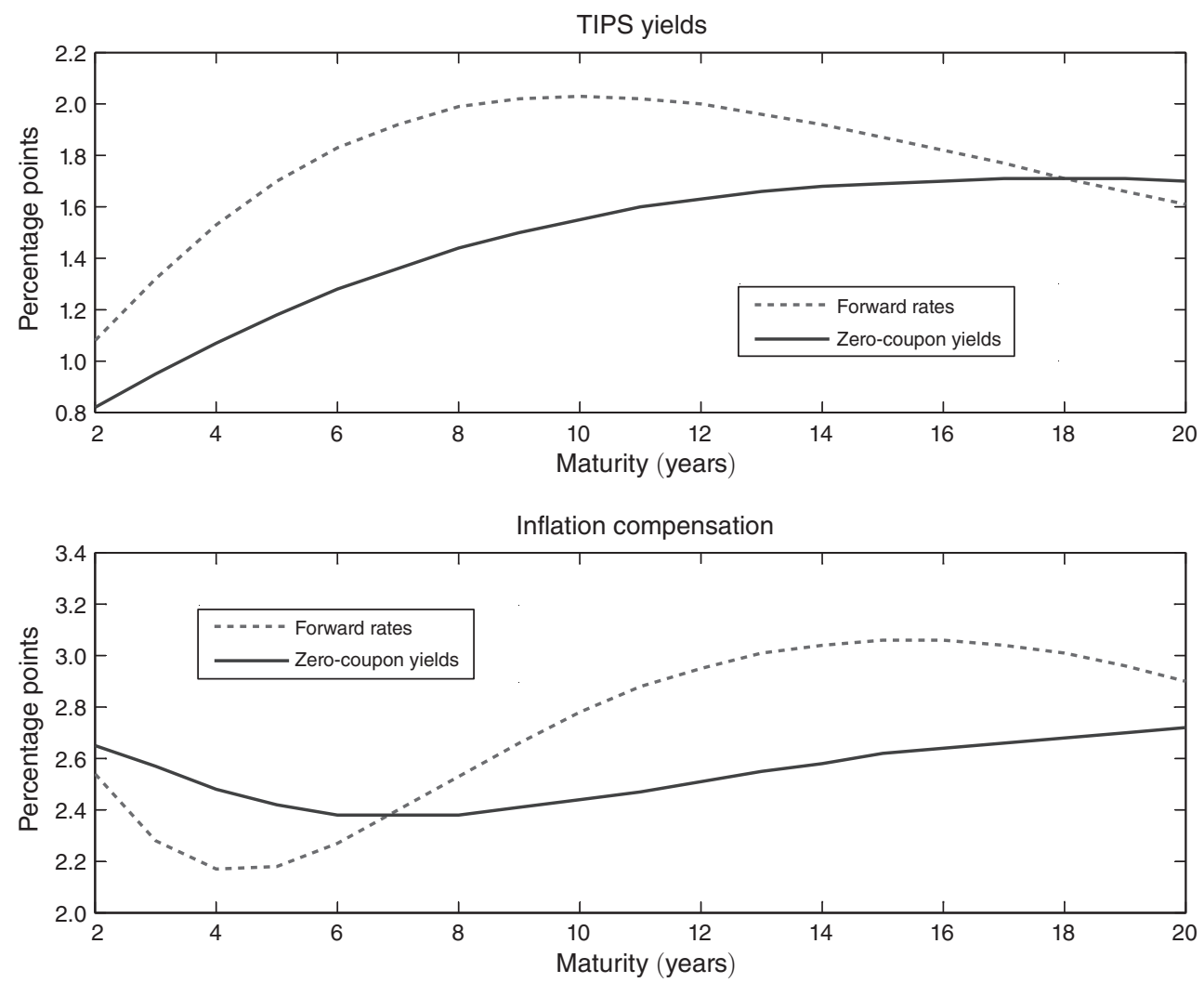

Figure 4. Zero-Coupon and Forward Rates on June 1, 2005

TIPS yields began to rise, as expected, but ten-year yields fell for a while, a phenomenon called the "conundrum" by former Federal Reserve Chairman Alan Greenspan and discussed in Don H. Kim and Wright (2005) and David K. Backus and Wright (2007).

The second half of 2007 and early 2008 were marked by the onset of turmoil in financial markets, and monetary policy was eased sharply to support economic growth. Accordingly, real rates plunged, with the five-year TIPS yield falling close to zero, and, indeed, shorter-term TIPS yields were negative. TIPS yields can and do fall below zero ${ }^{10}$ However, real yields rebounded starting in late 2008 , as financial market conditions continued to deteriorate, even though monetary policy was eased further. This could reflect expectations for greater bond issuance caused by the "bailout" of financial institutions. Also, it could reflect the greater premium that investors demanded to hold relatively less liquid TIPS securities at a time of financial market stress.

\footnotetext{
${ }^{10}$ The Treasury Department has issued rules on how a TIPS auction would be conducted in a negative real rate environment. The coupon would be set to zero, and TIPS would sell for below par value, at a price determined at auction. However, our fitted TIPS yields have never fallen below zero at the maturities at which the Treasury Department conducts auctions, and there has never been a negative-yield TIPS auction.
} 
5-year yields

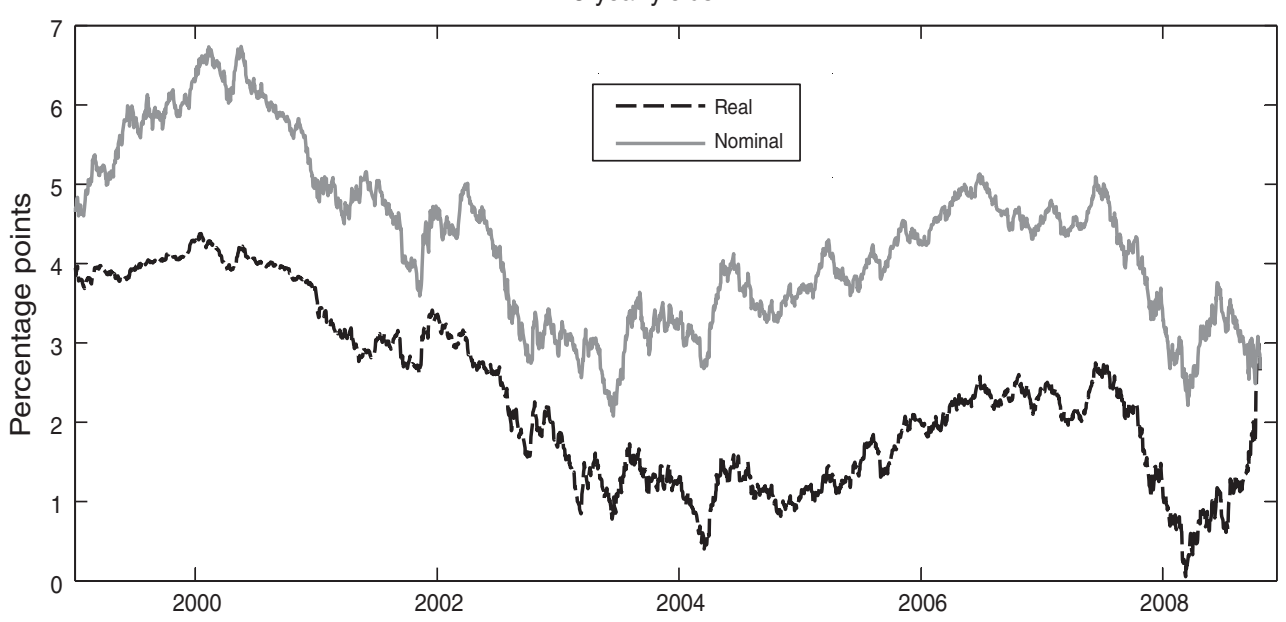

10-year yields

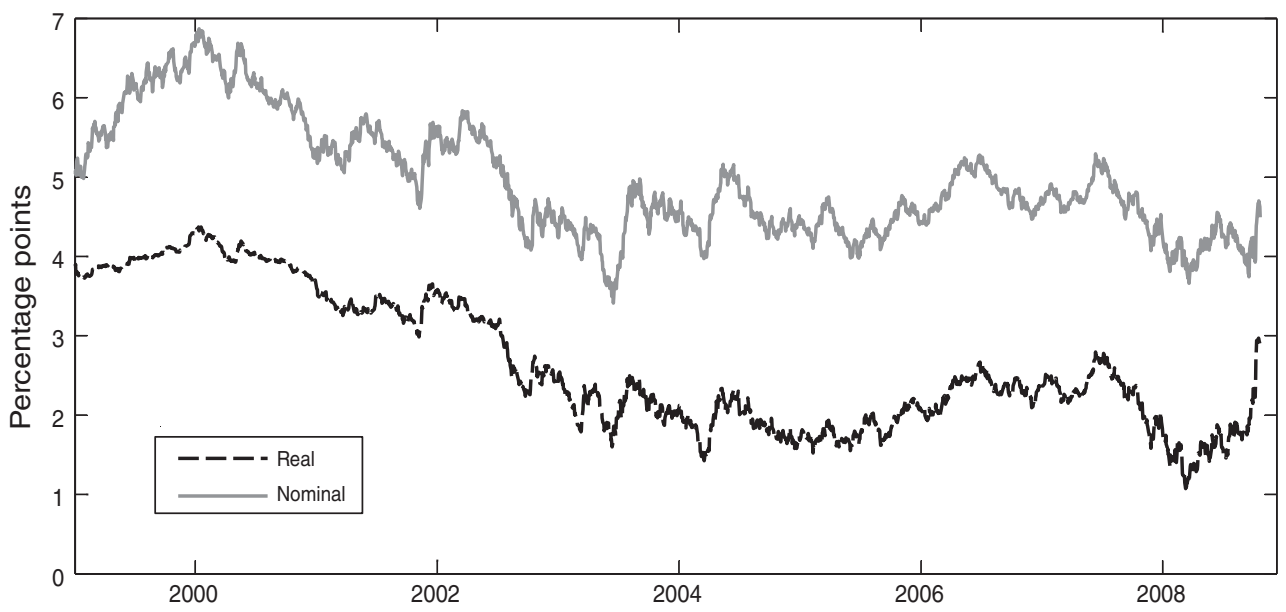

Figure 5. Zero-Coupon Yields: TIPS AND NominaL

The behaviors of 5- and 10-year zero-coupon and instantaneous forward inflation compensation over the sample are shown in Figure 6. Inflation compensation was quite low in 1999, reflecting the poor liquidity of TIPS relative to nominal securities (the counterpart of the high TIPS yields at that time). Breakeven inflation rates tended to drift higher through 2003, in part because of the improvement in TIPS liquidity. In addition, investors may have become more concerned about upside inflation risks by early 2004, in light of the updrift in realized inflation, the rebound in growth, and the continued accommodative stance of monetary policy.

At the very end of the sample period, five- and ten-year inflation compensation plummeted, presumably reflecting expectations for economic weakness to restrain inflation, and also, a further spike in the compensation that investors demand for the relatively low liquidity of TIPS. Distant-horizon forward measures of inflation 

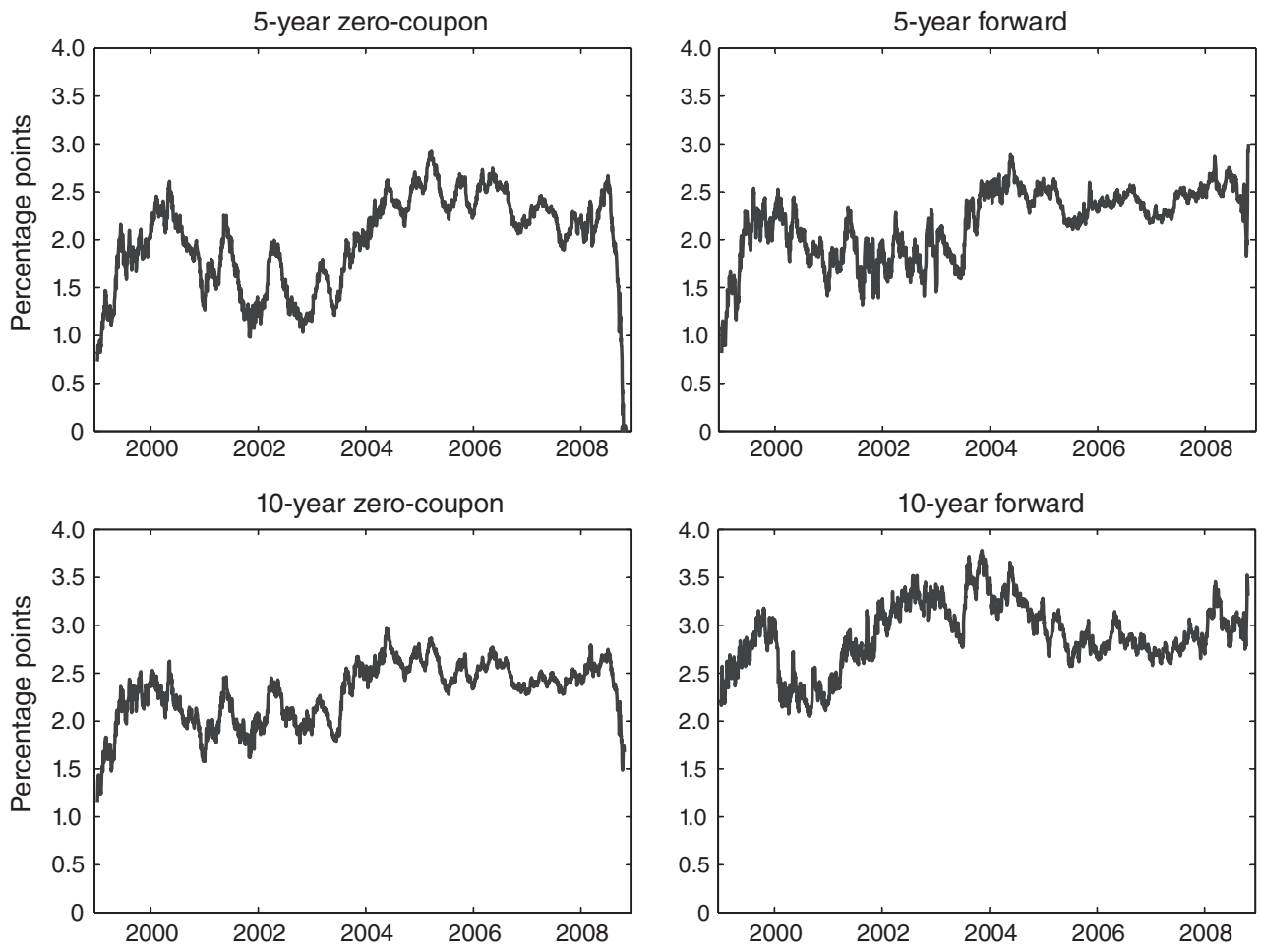

Figure 6. InFLATION COMPENSATION

compensation, however, increased somewhat, which could reflect a concern that the exceptional policy actions being undertaken in response to the credit crisis may lead to higher inflation in the long run.

One inflation compensation measure that is of particular interest is the five-year forward five-year rate (also known as the five-year five-year forward breakeven inflation rate), because it has been explicitly mentioned in speeches by a number of Fed policymakers. The behavior of this measure is often taken as a gauge of the Fed's inflation-fighting credibility. Policymakers seem to look to this measure to help judge whether near-term inflation pressures are working their way into longterm expectations. The concern is that such leakage would create a more persistent inflation problem that would be costly to reverse. If the Fed maintains its credibility, then the forward inflation compensation measure should be relatively unresponsive to information about the near-term outlook ${ }^{11}$ This measure, which can be derived from our yield curves as a par forward rate over a five-year horizon, is shown in Figure 7. It shares many of the same properties of the instantaneous forward rates discussed previously.

\footnotetext{
${ }^{11}$ The view that forward inflation compensation rates cannot be read as pure inflation expectations because of the presence of an inflation risk premium and a liquidity premium provides some room for the measure to vary without raising concerns among policymakers. However, risks to the inflation outlook are also important, and a large enough rise would be concerning to a central bank, regardless of whether it was driven by inflation expectations or investors' assessment of considerable upside inflation risks.
} 


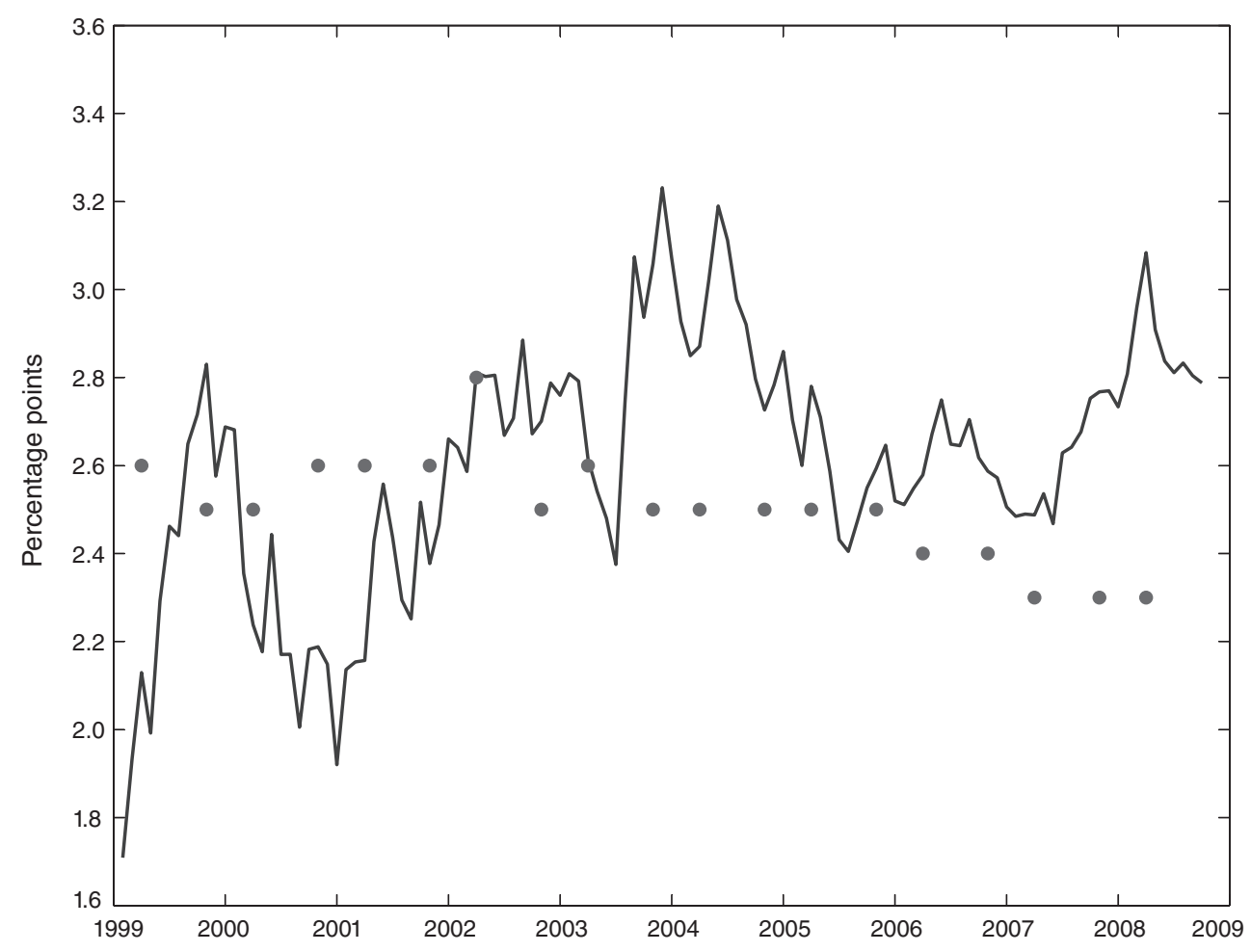

Figure 7. Five-to-Ten Year Forward Inflation Compensation and Blue Chip Forecasts

Notes: The solid line gives forward par inflation compensation. The dots are the Blue Chip survey inflation expectations.

The yield curve estimated above is intended to be flexible enough to capture the general shape of TIPS yields while smoothing through some of the factors that might affect individual securities. One such factor is the seasonality of CPI 12 Because TIPS are indexed to nonseasonally adjusted CPI, the yield on an individual security will reflect the expected seasonal change in the index ratio between the quote date (or more specifically the settlement date) and the maturity date of the security. This has two effects. It causes some variation in yields over time, as the seasonality of the quote date changes. And, it causes some variation across individual securities. For example, TIPS securities that mature in April tend to have higher yields and lower breakeven rates than those maturing in January because the CPI seasonal factor corresponding to the April maturity is much lower than that corresponding to the January maturity (reducing the price of the April TIPS and raising their yield). At longer maturities, the impact of the seasonal pattern gets amortized over a longer period, and is negligible, but it can be important at shorter horizons. The NSS yield curve, however, smoothes through this variation across maturity months. This

\footnotetext{
${ }^{12}$ Jacob Ejsing, Juan Angel Garcia, and Thomas Werner (2007) study the seasonal effect in euro area inflation compensation and show that for very short maturities the magnitudes involved are nontrivial.
} 
Table 1 -Description of the Series in the Data Appendix

\begin{tabular}{lccc}
\hline \hline Series & Compounding convention & Mnemonics & Maturities reported (max) \\
\hline TIPS yields & Continuously comp. & TIPSYXX & All integers 2-20 \\
Zero-coupon & Coupon-equivalent & TIPSPYXX & All integers 2-20 \\
Par & Continuously comp. & TIPSFXX & All integers 2-20 \\
Instantaneous forward & Coupon-equivalent & TIPS1FXX & 4 and 9 \\
One-year forward & Coupon-equvalent & TIPS5F5 & N/A \\
Five-to-ten-year forward & N/A & BETA0 to TAU2 & \\
Parameters & & & \\
& & & All integers 2-20 \\
Inflation compensation & Continuously comp. & BKEVENYXX & All integers 2-20 \\
Zero-coupon & Coupon-equivalent & BKEVENXX & All integers 2-20 \\
Par & Continuously comp. & BKEVENFXX & 4 and 9 \\
Instantaneous forward & Coupon-equivalent & BKEVEN1FXX & \\
One-year forward & Coupon-equivalent & BKEVEN5F5 & \\
Five-to-ten-year forward & Cond &
\end{tabular}

Notes: XX in each case denotes the maturity in years. For example, TIPSY10 denotes the ten-year zero-coupon yield. The one-year forward rates in XX years denote the one-year forward rates beginning XX years hence. For example, TIPS1F09 is the one-year forward rate from nine to ten years hence. The parameters are labeled BETA0, BETA1, BETA2, BETA3, TAU1, and TAU2, corresponding to the equations in the text. Note that the parameters BETA 3 and TAU2 are restricted to zero in the earlier part of the sample, as discussed in the text.

feature is desirable for our curve, as it is designed to extract information about macroeconomic expectations and risks. ${ }^{13}$

The Appendix on the Federal Reserve Web site www.federalreserve.gov/ econresdata/researchdata.htm provides data on zero-coupon yields (continuously compounded), instantaneous forward rates (continuously compounded), and par yields (coupon-equivalent) for TIPS securities at a range of maturities, as well as the five-year forward par five-year TIPS yield (coupon-equivalent). The maturities included span 5-20 years for the period through 2004, and 2-20 years since 2004 (when we use the more flexible specification, as discussed above). Yields at maturities below five years are not reported before the end of 2004 because, as can be seen in Figure 1, this would, at times, have entailed extrapolating the TIPS yield curve outside of the range of maturities that were actually outstanding. Meanwhile, yields for maturities below two years are never reported because the shortest maturity TIPS are excluded from our smoothed yield curve due to the effects of the indexation lag and seasonality in the CPI.

The data are daily and are available back to January 4, 1999. The online Appendix also includes estimates of the six parameters of the NSS TIPS yield curve and the zero-coupon, instantaneous forward and par rates of inflation compensation, and the five-year forward five-year rate of inflation compensation. This Appendix uses mnemonics described in Table 1 . The data will be updated regularly as a resource for academic researchers and financial market practitioners.

\footnotetext{
${ }^{13}$ One might design a different curve, or append this one with additional analysis, if the main purpose is to gauge the relative value of specific securities.
} 


\section{Inflation Compensation and Inflation Expectations}

Inflation compensation is a mechanical calculation of the level of inflation which, if realized, would give investors the same return on TIPS and nominal Treasury securities. It is often used as a measure of inflation expectations, but this is correct only if investors are risk neutral, and there is no liquidity premium. Our interpretation of movements in inflation compensation has stressed the existence of factors other than inflation expectations. In this section, we provide some further analysis supporting the view that variation in the inflation risk premium and the liquidity premium are also part of the behavior of inflation compensation. Inflation compensation is inflation expectations plus an inflation risk premium minus a liquidity premium that investors demand to hold comparatively less liquid TIPS securities.

\section{A. The Volatility of Forward Inflation Compensation Rates}

In this subsection, we address whether distant-horizon forward rates of inflation compensation can be viewed simply as measures of the long-run expected level of inflation, or the implicit inflation target of the central bank. If a ten-year forward rate of inflation compensation really is the rational long-run expectation of inflation, then it should be a martingale. Otherwise, the expectation of the long-run expectation of inflation tomorrow would differ from the long-run expectation of inflation today, which is impossible under rational expectations by the law of iterated expectations.

More precisely, let $\pi_{t}^{f}(10)$ and $\pi_{t}^{f}(10-)$ denote the ten-year and ten-year-lessone-day forward rates of inflation compensation. ${ }^{14}$ If the forward rates of inflation compensation represent inflation expectations, then $E_{t}\left(\pi_{t+1}^{f}(10-)-\pi_{t}^{f}(10)\right)=0$, and $x_{t}=\pi_{t+1}^{f}(10-)-\pi_{t}^{f}(10)$ is a martingale difference sequence. This hypothesis can be tested by a variance ratio test. Table 2 shows the standard deviation of $x_{t}$ and $\sum_{j=1}^{k} x_{t+j}$, where $k$ is 22,66 , or 132 , corresponding to 1,3 and 6 months, respectively. The standard deviation of a one-day change in forward inflation compensation is a bit less than five basis points. If $x_{t}$ is a martingale difference sequence, then the variance of $\sum_{j=1}^{k} x_{t+j}$ must be $k$ times the variance of $x_{t}$. Table 2 reports variance ratio statistics testing this hypothesis. The test statistic is $z^{*}(q)$ in the notation of Andrew W. Lo and A. Craig Mackinlay (1988), which means that it is the variance ratio statistic that allows for time-varying conditional heteroskedasticity. Under the martingale hypothesis, this test statistic has a standard normal asymptotic distribution. However, in Table 2, we see that the test rejects in the left tail, meaning that the volatility of longer term changes in inflation compensation is too small relative to the volatility of daily changes for inflation compensation to be a martingale 15 This, in turn, means there is some tendency to mean reversion in forward inflation compensation. When it is high, it subsequently falls, and vice-versa.

\footnotetext{
${ }^{14}$ The ten-year-less-one-day rate of inflation compensation can be obtained from our parametric yield curves, assuming 260 business days in a year.

${ }^{15}$ It is well-known that the distribution of this test statistic can be quite far from being standard normal in small sizes (Lo and Mackinlay 1988; Matthew Richardson and James H. Stock 1989). However, those papers find that the left-tail percentiles of the small sample distribution are above their asymptotic counterparts. Under these circumstances, the fact that we reject in the left tail is all the stronger evidence against the martingale hypothesis.
} 
Table 2-Volatility of Changes in Ten-Year Forward Inflation COMPEnSATION at Selected Horizons

\begin{tabular}{lcc}
\hline \hline Horizons & Standard deviation (basis points) & Variance ratio statistic \\
\hline One day & 5.6 & \\
One month & 18.8 & $-3.67^{* *}$ \\
Three months & 26.7 & $-2.86^{* *}$ \\
Six months & 32.6 & $-2.35^{* *}$ \\
\hline
\end{tabular}

Notes: This table shows the standard deviation of one-day and one-, three-, and six-month cumulative values of $x_{t}=\pi_{t+1}^{f}(10-)-\pi_{t}^{f}(10)$. They are computed assuming 22 days per month. The variance ratio statistic is the heteroskedasticity robust test statistic of Lo and MacKinlay (1988), and has a standard normal asymptotic distribution. The number of daily observations is 2,449 .

*** Significant at the 1 percent level.

** Significant at the 5 percent level.

* Significant at the 10 percent level.

Stock and Mark W. Watson (2007) find that an unobserved components model with stochastic volatility provides good forecasts for inflation. The model is a univariate model in which inflation is the sum of a martingale permanent component and a martingale difference sequence transitory component. The variance of the innovations to both components is allowed to be time-varying. At any point in time, the forecast of future inflation at any horizon is equal to the estimated permanent component. And the volatility of that forecast is the volatility of the permanent component. Stock and Watson (2007) find the volatility of the permanent component was high in the early 1980s, but has fallen since. Estimating this model on headline CPI has averaged 20 basis points per quarter since the start of 1999. The standard deviation of one-day changes in ten-year inflation compensation is 5.6 basis points. So, if we interpret ten-year inflation compensation as a long-run inflation measure, and appeal to the martingale property that this implies, then the volatility of quarterly changes in long-run inflation expectations should be 45 basis points per quarter, which is more than twice as big as the time-series estimate. Again, it appears that inflation compensation is too volatile at high frequency to represent inflation expectations alone.

\section{B. Comparison to Surveys of Inflation Expectations}

Twice a year, in March and October, Blue Chip Economic Indicators collects long-range forecasts of CPI inflation, five to ten years hence, from a large number of professional forecasters. It seems worthwhile to compare the survey results with average five-to-ten year forward inflation compensation in each of the survey months. After all, at least at shorter horizons, surveys have been remarkably accurate predictors of future inflation (Andrew Ang, Geert Bekaert, and Min Wei 2007).

Figure 7 shows the time series of the mean survey forecast, in addition to five-toten year forward inflation compensation. Inflation compensation has been far more volatile than survey expectations, and the two have no consistent relationship with each other. Since 2002, survey expectations have been consistently below inflation compensation, suggesting that the inflation risk premium (which pushes inflation 
compensation up) now outweighs the TIPS liquidity premium (which pushes inflation compensation down) ${ }^{16,17}$

It is also of interest to study the association between inflation compensation and investors' uncertainty about inflation. Macroeconomic uncertainty is very hard to measure, and we are not aware of any survey asking respondents for density forecasts at long horizons. But, the dispersion of long-horizon survey responses may serve as a crude proxy for uncertainty 18 The Blue Chip surveys report a simple dispersion measure for their long-horizon survey questions, which is the difference between the average of the ten highest forecasts and the average of the ten lowest forecasts. Figure 8 plots the time series of this dispersion measure for CPI and five-to-ten year forward inflation compensation. There is a remarkable, positive association between these two variables. In fact, the correlation between the survey dispersion and five-to-ten year forward inflation compensation in the survey months is 0.71 , which seems reasonable if inflation compensation represents, in part, a risk premium that compensates investors for uncertainty about future inflation.

\section{Decomposing Inflation Compensation}

The previous section showed evidence that inflation compensation is not a pure measure of inflation expectations. In this section, we attempt to decompose inflation compensation into its components: inflation expectations, the liquidity premium, and the inflation risk premium.

\section{A. The Liquidity Premium}

We estimate the TIPS liquidity premium by regressing inflation compensation on measures of liquidity, following authors such as Long Chen, David A. Lesmond, and Jason Wei (2007), who estimated the effects of liquidity on corporate yield spreads in this way 19 We use two measures of the relative liquidity of the nominal and index-linked bond markets 20 The first is the trading volume among primary dealers in TIPS, expressed as a share of total Treasury trading volume, from the FR-2004 survey of primary dealers conducted by the Federal Reserve Bank of New York. This share rose from about 0.5 percent in 1999 to about 2 percent in 2006, as

\footnotetext{
${ }^{16}$ Our nominal yield curve does not include on-the-run issues, and, so, our inflation compensation numbers are not distorted by the large and time-varying liquidity premia associated with these securities. Nonetheless, to the extent that TIPS are still less liquid than off-the-run nominal securities, inflation compensation may be pushed down by a premium to compensate investors for the differential liquidity of nominal and TIPS securities.

${ }^{17}$ This pattern has implications for the cost of TIPS issuance. In the early years of the TIPS program, TIPS were more expensive than nominal Treasury securities, in terms of their expected servicing cost to the Treasury, as argued by Sack and Elsasser (2004). However, with breakevens moving above expected inflation, the relative costs have been reversed for securities issued more recently, as pointed out by Jennifer E. Roush (2007).

${ }^{18}$ Gürkaynak and Justin Wolfers (2007) show that for several macroeconomic data releases the uncertainty and heterogeneity of beliefs are positively correlated, but that these correlations are not very high. The dispersion of survey answers is likely to capture some element of underlying uncertainty, but is an imperfect measure.

${ }^{19}$ Chen, Lesmond, and Wei (2007) control for measures of default risk. But since both the bonds we are considering are issued by the Treasury, there is no need to control for default risk.

${ }^{20}$ Ideally, we would use bid-ask spreads in the TIPS market, but, unfortunately, we do not have access to such data.
} 


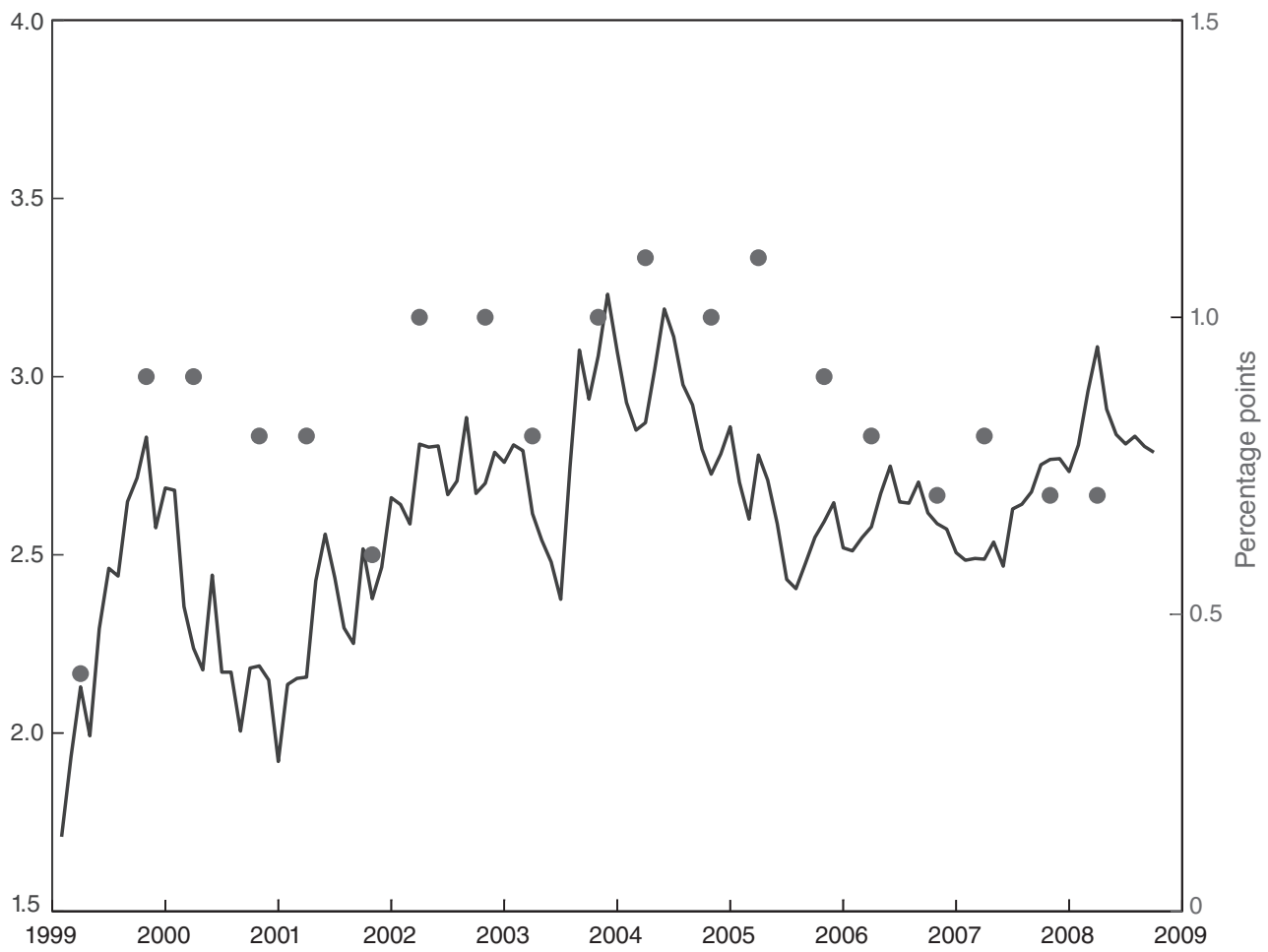

Figure 8. Five-to-Ten Year Forward Inflation Compensation and Blue Chip Forecast Dispersion

Notes: The solid line gives forward par inflation compensation (scale on the left). The dots are the dispersion of forecasts from the Blue Chip survey (scale on the right).

the TIPS market developed, but it remains smal. ${ }^{21}$ The second is the spread between Resolution Funding Corporation (Refcorp) strips and Treasury strips. Refcorp issued bonds to finance the resolution of the Savings and Loan crisis. These bonds are guaranteed by the Treasury and have the same credit risk as Treasury securities, but they are considerably less liquid than Treasuries.22 Thus, the spread between Refcorp and Treasury strips is a very direct indicator of the liquidity premium in the Treasury market, and has been used as such by Francis A. Longstaff (2004). Of course, this measures the liquidity premium that investors demand to hold Refcorp bonds rather than nominal Treasury securities, which need not necessarily be the same as the liquidity premium that they demand to hold TIPS. Nonetheless, it seems reasonable to suppose that the Refcorp spread and TIPS liquidity premium should be highly correlated, as authors such as Tarun Chordia, Asani Sarkar, and Avanidhar Subrahmanyam (2005) have argued that there is considerable commonality in liquidity premia, even across quite different markets (including stock and bond

${ }^{21}$ TIPS constitute about 10 percent of Treasury issues outstanding, so their share in trading volume is well below their share in total supply of Treasury securities.

${ }^{22}$ To be precise, they have principal payments that are fully collateralized by nonmarketable Treasury securities and coupon payments that are explicitly guaranteed by the Treasury. Also, they have the same tax treatment as Treasuries (subject to Federal tax and exempt from state and local tax). 
Table 3-Regression Results for Estimating Liquidity Premia in Five- and Ten-Year Inflation COMPENSATION

\begin{tabular}{lcc}
\hline \hline Predictor & Five-year & Ten-year \\
\hline TIPS relative volume & 0.51 & 0.40 \\
& $(0.09)$ & $(0.06)$ \\
Refcorp spread & -1.67 & -0.78 \\
& $(0.64)$ & $(0.34)$ \\
$R^{2}$ & 0.422 & 0.424 \\
\hline
\end{tabular}

Notes: This table reports the results from regressions of five- and ten-year inflation compensation (in percentage points) onto the TIPS volume, as a share of total Treasury Primary Dealer trading volume (in percentage points), and the spread of 20-year Refcorp strips over their Treasury counterparts (in percentage points). Newey-West standard errors with a lag truncation parameter of 20 are shown in parentheses. The number of observations is 2,450 .

markets). Note that while our first measure (relative trading volumes) captures a physical measure of trading intensity, the second measure captures possibly timevarying prices of illiquidity as well.

We regressed five- and ten-year inflation compensation on these two liquidity measures jointly. The regression results are shown in Table 3. Both are significant with the expected sign at the five- and ten-year horizons. Rising TIPS volumes boost inflation compensation, while an increase in the Refcorp spread lowers inflation compensation. The fitted values from this regression represent our measure of the time-varying effect of liquidity on inflation compensation. It does not, however, identify the level of the liquidity effect. We normalize this to zero in April 2005, meaning that we are measuring the liquidity premium relative to its value at that time (which was the period when the TIPS liquidity premium was estimated to be the lowest in our sample). The estimated liquidity premium on five- and ten-year TIPS is shown in Figure 9. In this figure, the sign of the liquidity premium has been flipped so that it measures the extra yield that investors demand to hold TIPS rather than nominal securities. A high liquidity premium drives inflation compensation down.

The estimated liquidity premium in yield terms is larger at the five- than at the ten-year horizon. The liquidity premium was high in the early years of the TIPS program, but fell fairly steadily between 1999 and 2005. During the recent period of financial market turmoil, the liquidity premium rose considerably, and it soared in September 2008, reaching about the same level as in 1999 when the TIPS market was small and still relatively new.

\section{B. Extracting Inflation Expectations}

We finally aim to construct a series of inflation expectations purged, to the extent possible, of liquidity and risk effects. This is a challenging task given the short sample period, but we attempt to do so using a state-space model in which survey expectations are treated as noisy measures of inflation expectations.

Concretely, we take the inflation compensation series at either the five- or ten-year horizon, adjusted by the liquidity premium as estimated in subsection $V(A), \pi_{t}^{A D J}$, and assume that this represents the sum of inflation expectations and an inflation risk premium: 


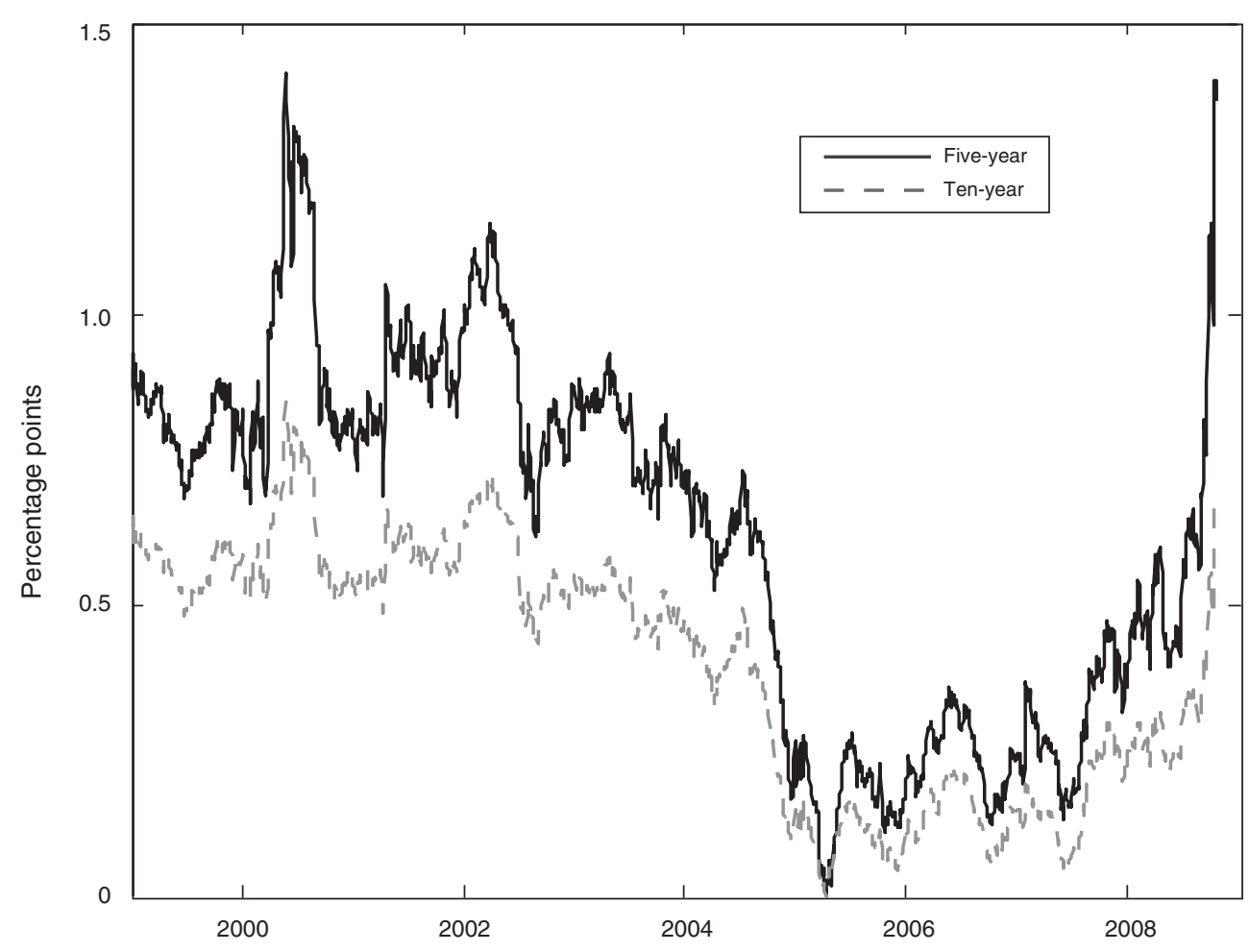

Figure 9. Estimated TIPS LiQuidity Premium

Notes: Regression-based estimates of the liquidity premium for holding TIPS, relative to that for nominal securities, constructed as described in the text, normalized to zero in April 2005. The regression coefficient estimates are shown in Table 3.

$$
\pi_{t}^{A D J}=\pi_{t}^{E X P}+\pi_{t}^{R P}
$$

Both the Survey of Professional Forecasters (SPF) and Blue Chip periodically ask respondents to forecast inflation over the next five and ten years. We assume that on the days of SPF surveys ${ }^{23}$ the survey expectation of inflation at the five- or ten year horizon, $\pi_{t}^{S P F}$, can be written as a noisy measure of latent inflation expectations:

$$
\pi_{t}^{S P F}=\pi_{t}^{E X P}+u_{t}^{S P F},
$$

where $u_{t}^{S P F}$ is an independently and identically distributed measurement error. Likewise, on the days of long-horizon Blue Chip surveys, the survey expectation of inflation, $\pi_{t}^{B C}$, is assumed to be

$$
\pi_{t}^{B C}=\pi_{t}^{E X P}+u_{t}^{B C}
$$

\footnotetext{
${ }^{23}$ The SPF is conducted around the start of each February, May, August, and November. We treat the first business day of each month as the survey date. Likewise, the long-horizon Blue Chip surveys are conducted around the start of each March and October, and we treat the first business day of each month as the survey date.
} 
where $u_{t}^{B C}$ is an independently and identically distributed measurement error with a separate variance. The combination of equations (5), (6), and (7) gives us the measurement equations for a system in state space form, where $\left(\pi_{t}^{E X P}, \pi_{t}^{R P}\right)^{\prime}$ is the state vector. On most days, the survey expectations are treated as missing data. The transition equation assumes that long-run inflation expectations can be approximated by a random walk (motivated by the model of Stock and Watson 2007), while the inflation risk premium is an $\mathrm{AR}(1)$, so that the transition equation is

$$
\left(\begin{array}{l}
\pi_{t}^{E X P} \\
\pi_{t}^{R P}
\end{array}\right)=\left(\begin{array}{ll}
1 & 0 \\
0 & \varphi
\end{array}\right)\left(\begin{array}{c}
\pi_{t-1}^{E X P} \\
\pi_{t-1}^{R P}
\end{array}\right)+\left(\begin{array}{l}
v_{1 t} \\
v_{2 t}
\end{array}\right),
$$

where $v_{1 t}$ and $v_{2 t}$ are independently and identically distributed, mutually uncorrelated random variables with mean zero and variances $\sigma_{1}^{2}$ and $\sigma_{2}^{2}$, respectively. We set $\sigma_{1}^{2}$ to its estimated average value since 1999 from fitting the model of Stock and Watson to actual CPI inflation data. The Kalman filter can be used to estimate the remaining model parameters by maximum likelihood, and smoothed estimates of inflation expectations can be extracted. ${ }^{24}$

Figure 10 shows the five- and ten-year inflation expectations obtained in this way. Our estimates of inflation expectations generally moved in a fairly narrow range over this period. Inflation expectations were low at the start of the sample, which may partly owe to a difficulty in fully adjusting for the effects of poor liquidity at that time. Inflation expectations fell in 2003, at the time of the "deflation scare," before rebounding as the economy grew. Expected inflation also rose during most of the recent period of financial market turmoil, which is consistent with a view that the FOMC was focusing on supporting growth at the expense of its inflation objective. However, at the end of the sample, our measure of inflation expectations fell sharply. Extracting macroeconomic expectations implicit in asset prices is particularly challenging in the fall 2008, but this could be because agents expect a severe and longlasting recession to restrain aggregate demand and inflation going forward-a view also echoed by policymakers.

\section{Conclusion}

In this paper, we have estimated the US TIPS yield curve using an approach that is simple and parsimonious. The methodology is quite effective at capturing the general shape of the yield curve while smoothing through idiosyncratic variation in the yields of individual inflation-protected securities. The estimated yield curve can be expressed in a variety of ways, including zero-coupon yields, par yields, and

\footnotetext{
${ }^{24}$ The inflation risk premium can also be extracted, though this is only identified up to a constant because the liquidity premium has only been identified up to a constant. Meanwhile, the assumption that the surveys measure inflation expectations correctly, on average, identifies the level of inflation expectations.
} 


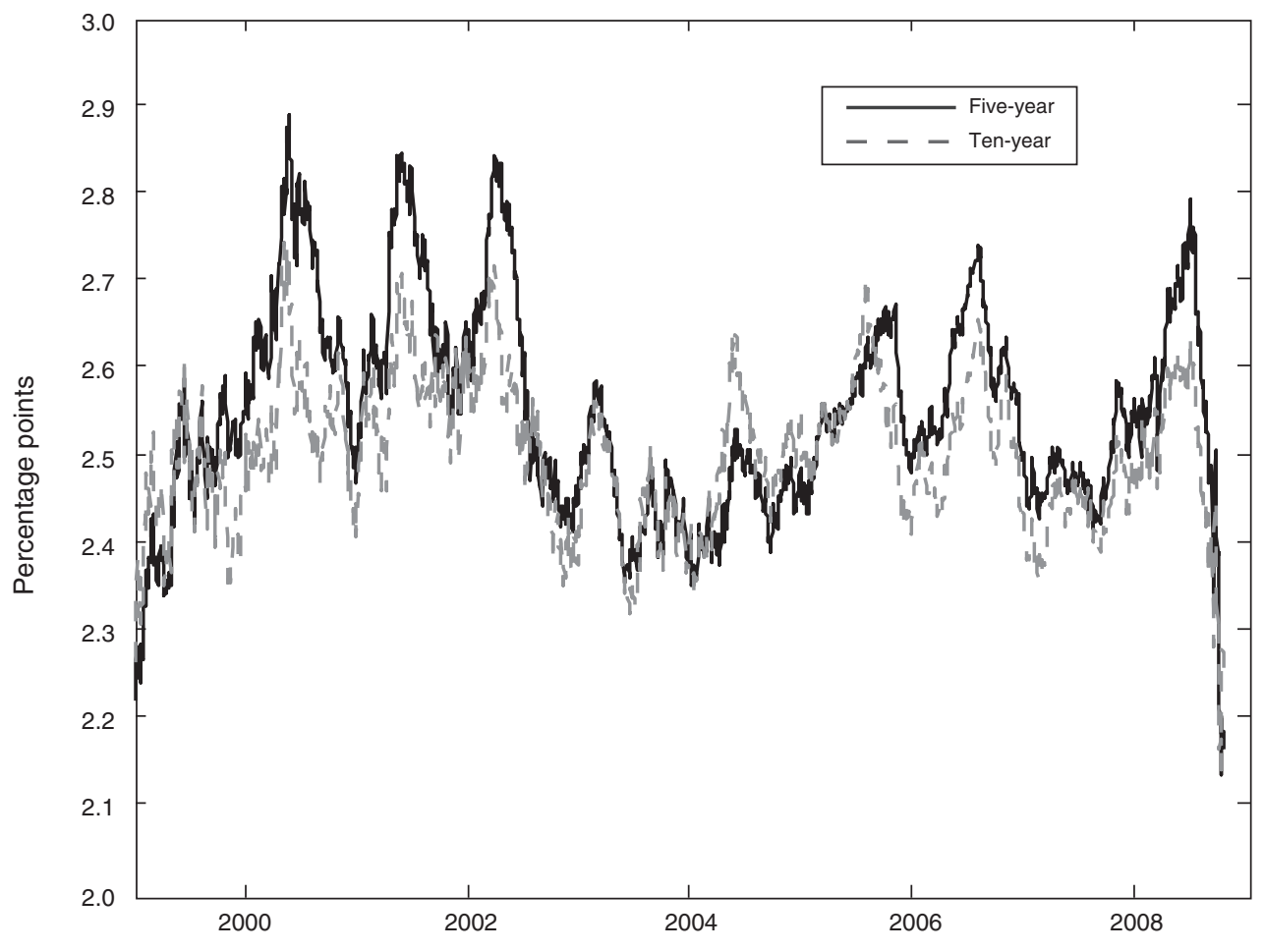

Figure 10. Estimated Inflation Expectations

Note: Estimates of inflation expectations at five- and ten-year horizons obtained from the Kalman smoother applied to the inflation compensation series adjusted for liquidity effects.

forward rates. And, it can be compared to the corresponding nominal yield curve to obtain estimates of inflation compensation.

Having the real yield curve should provide tremendous benefits to our efforts to better understand the behavior of nominal yields. It allows us to parse nominal yields and forward rates into their real rate component and their inflation compensation component. These two components may behave quite differently, in which case, simply looking at a nominal yield might mask important information. Inflation compensation is a useful measure, because it is the only high frequency measure of the market's concerns about inflation. Nonetheless, we argue that it embodies nontrivial and time-varying liquidity and inflation risk premia. Thus, research on understanding not only the mean, but the distribution of perceived future inflation outcomes, and the prices of risk associated with these, is an important part of understanding the behavior of inflation compensation and the nominal yield curve. We have taken a step in that direction by showing one way to decompose inflation compensation into its inflation expectations, inflation risk premium, and liquidity premium components.

We hope that our TIPS yield curve will be useful to researchers in further work that combines macroeconomics and finance. It is to this end that we have made the full dataset available to be downloaded at www.federalreserve.gov/econresdata/ researchdata.htm. These data will be updated periodically. 


\section{REFERENCES}

Ang, Andrew, Geert Bekaert, and Min Wei. 2007. "Do Macro Variables, Asset Markets, or Surveys Forecast Inflation Better?” Journal of Monetary Economics, 54(4): 1163-1212.

Backus, David K., and Jonathan H. Wright. 2007. "Cracking the Conundrum.” Brookings Papers on Economic Activity, 38(1): 293-329.

Barr, David G., and John Y. Campbell. 1997. "Inflation, Real Interest Rates, and the Bond Market: A Study of UK Nominal and Index-Linked Government Bond Prices." Journal of Monetary Economics, 39(3): 361-83.

Bliss, Robert R. 1996. "Testing Term Structure Estimation Methods." In Advances in Futures and Options Research, Vol. 9, ed. P. Ritchken, P. P. Boyle, and G. Pennacchi, 197-231. Greenwich, CT: JAI Press.

Chen, Long, David A. Lesmond, and Jason Wei. 2007. "Corporate Yield Spreads and Bond Liquidity." Journal of Finance, 62(1): 119-49.

Chordia, Tarun, Asani Sarkar, and Avanidhar Subrahmanyam. 2005. "An Empirical Analysis of Stock and Bond Market Liquidity." Review of Financial Studies, 18(1): 85-129.

Cochrane, John H., and Monika Piazzesi. 2008. "Decomposing the Yield Curve." faculty.chicagogsb.edu/john.cochrane/research/Papers/interest_rate_revised.pdf.

Ejsing, Jacob, Juan Angel Garcia, and Thomas Werner. 2007. "The Term Structure of Euro Area Break-Even Inflation Rates: The Impact of Seasonality.” European Central Bank Working Paper 830.

Gürkaynak, Refet S., Brian Sack, and Jonathan H. Wright. 2007. "The U.S. Treasury Yield Curve: 1961 to the Present." Journal of Monetary Economics, 54(8): 2291-2304.

Gürkaynak, Refet S., and Justin Wolfers. 2007. "Macroeconomic Derivatives: An Initial Analysis of Market-Based Macro Forecasts, Uncertainty, and Risk." In NBER International Seminar on Macroeconomics 2005, ed. Jeffrey A. Frankel and Christopher A. Pissarides, 11-50. Cambridge, MA: MIT Press.

Kim, Don H., and Jonathan H. Wright. 2005. "An Arbitrage-Free Three-Factor Term Structure Model and the Recent Behavior of Long-Term Yields and Distant-Horizon Forward Rates." Board of Governors of the Federal Reserve System Finance and Economics Discussion Series 2005-33.

Lo, Andrew W., and A. Craig Mackinlay. 1988. "Stock Market Prices Do Not Follow Random Walks: Evidence from a Simple Specification Test." Review of Financial Studies, 1(1): 41-66.

Longstaff, Francis A. 2004. "The Flight-to-Liquidity Premium in U.S. Treasury Bond Prices." Journal of Business, 77(3): 511-26.

Nelson, Charles R., and Andrew F. Siegel. 1987. "Parsimonious Modeling of Yield Curves." Journal of Business, 60(4): 473-89.

Richardson, Matthew, and James H. Stock. 1989. "Drawing Inferences from Statistics Based on Multiyear Asset Returns." Journal of Financial Economics, 25(2): 323-48.

Roush, Jennifer E. 2007. "The Cost of TIPS Issuance." Unpublished.

Sack, Brian, and Robert Elsasser. 2004. "Treasury Inflation-Indexed Debt: A Review of the U.S. Experience.” Federal Reserve Bank of New York Economic Policy Review, 10(1): 47-63.

Stock, James H., and Mark W. Watson. 2007. "Why has U.S. Inflation Become Harder to Forecast?" Journal of Money, Credit, and Banking, 39: 3-33.

Svensson, Lars E. O. 1994. "Estimating and Interpreting Forward Interest Rates: Sweden 1992-1994." National Bureau of Economic Research Working Paper 4871. 